International Institute for Applied Systems Analysis • A-2361 Laxenburg • Austria Tel: +432236807• Fax: +43223671313• E-mail: info@iiasa.ac.at•Web: www.iiasa.ac.at

INTERIM REPORT IR-97-081 / December 1997

\title{
Demand Dynamics With Socially Evolving Preferences
}

Roberta Aversi (r.aversi@finsiel.it)

Giovanni Dosi (dosi@iiasa.ac.at)

Giorgio Fagiolo (fagiolo@datacom.iue.it)

MaraMeacci (meacci@oxfor.uk)

Claudia Olivetti (olivetti@upenn.edu)

\section{Approved by}

Gordon MacDonald (macdonald@ilasa.ac.at)

Director, IIASA

Interim Reports on work of the International Institute for Applied Systems Analysis receive only limited review. Views or opinions expressed herein do not necessarily represent those of the Institute, its National Member Organizations, or other organizations supporting the work. 


\author{
About the Authors \\ Roberta Aversi, Finsiel, Rome, Italy. \\ Giovanni Dosi, Department of Economics, University of Rome "La Sapienza" and IIASA, \\ Laxenburg, Austria. \\ Giorgio Fagiolo, European University Institute, Florence, Italy. \\ Mara Meacci, Oxford University, UK. \\ Claudia Olivetti, University of Pennsylvania, USA.
}




\section{Acknowledgments}

Support to the research, at various stages, by the Italian Ministry of Research (MURST, "Progetti 40\%"), the Italian National Research Council (CNR), and the International Institute of Applied Systems Analysis (IIASA), Laxenburg, Austria, is gratefully acknowledged. Marianna Vintiadis has provided a very knowledgeable assistant researchship, and S. Crivellini has been a uniquely valuable support to the implementation of the simulation program. Endless discussions with Luigi Marengo and Helénè Tordjman have contributed to imprint the importance of cognitive representations in economic behaviours. Comments by Geoffrey Hodgson have been very useful in shaping this version of the work. The usual caveats of course apply. 


\section{Contents}

1 Introduction 1

2 Toward a Descriptive Theory of Consumption: Some Building Blocks 5

3 The Model $\quad 9$

4 A Preliminary Look At Some Statistical Properties $\quad 14$

5 Conclusions $\quad 18$ 


\title{
Demand Dynamics With Socially Evolving Preferences
}

\author{
Roberta Aversi (r.aversi@finsiel.it) \\ Giovanni Dosi (dosi@iiasa.ac.at) \\ Giorgio Fagiolo(fagiolo@datacom.iue.it) \\ Mara Meacci (meacci@oxfor.uk) \\ Claudia Olivetti (olivetti@upenn.edu)
}

\section{Introduction}

In this work we begin to explore some aggregate dynamic properties of demand patterns when preferences are shaped by the cognitive structures of consumers and evolve in socially embedded fashions.

A while ago, one of the authors of this paper witnessed at a seminar the horror of most colleagues when Werner Hildebrand, presenting some further development on his theory of demand (Hildebrand (1994)) provocatively suggested more or less that "preferences and choices are matters for psychiatrists and not for economists", while the task of the latter should be primarily to establish some statistical conditions under which basic propositions of economic theory - such as downward sloping demand curves etc. - hold in the aggregate, in presence of heterogeneous, and possibly "irrational" consumers. In a nutshell, the provocation highlights, first of all, a major divide cutting across the economic discipline as well as other social sciences -, namely, how seriously should one take standard utility theory (with or without its more recent refinements) and the associated "rational" theory of decision making as the foundation of a descriptive theory of demand? (Another major problem concerns the aggregate properties of diverse demand schedules, no matter how constructed: we shall come to that below.)

Needless to say, the majority of the economic profession seems to take that type of microeconomic foundations of decisions very seriously indeed, entrenched as they are with deep ("anthropological") views on the nature of "rationality" and self-seeking behaviours, passed through successive generations via conventional teaching tools such as "indifference curves" and the like, and further justified by their purported role in bridging descriptive and normative analyses (welfare theorems, etc.). However, admittedly minority views in economics (but nearly "mainstream" in other social disciplines) claim that classic decision theory has little to offer by way of the interpretation of what people actually do and that one should turn in fact to cognitive and social psychology, sociology (and, why not, psychiatry) in order to derive empirically sound theories of how people behave and choose the way they do.

Note that the appeal to inductive generalizations - in this perspective - does not concern solely the nature and origins of preferences (which could, as such, nicely complement rather than upset "rational" decision-theoretic views: after all, in the latter, as reminded by Stigler and Becker (1977), de gustibus non est disputandum ...). More profoundly, it 
relates to both the procedures by which decisions are taken and the interactions (possibly at a collectively level) between decisions, outcomes and preferences themselves.

First, at a procedural level, as Legrenzi, Girotto and Johnson-Laird (1993) put it,

"the classical theory of decision-making, whatever its status as a specification of rationality, does not begin to explain the mental processes underlying decisions ... On the one hand, the theory is radically incomplete: it has nothing to say about when one should decide to make a decision, or how one should determine the range of options, or how one should assess the utilities of various outcomes. On the other hand, the theory conflicts with the evidence on how people reach decisions in daily life" (Legrenzi et al. (1993) pp.37-8).

The literature on these subject is immense: see, among others, Slovic (1990), Payne, Bettman and Johnson (1992), Tversky and Kahneman (1986), Thaler (1992) ${ }^{1}$ In economics, as known, the emphasis on the "bounds" of rationality, and the related analytical requirement, so to speak, to "open up the cognitive blackbox", has found a good deal of inspiration in the path-breaking work of Herbert Simon (Simon ((1959), (1986) amd (1988)). Indeed, the empirical departures from the canonic procedures prescribed by rational decision theory are likely to be even deeper than those envisaged by Simon, in that human agents might not only be bound away from "substantive" rationality, but often display also systematic biases in the procedures themselves for judgment and choice. ${ }^{2}$ Moreover, as Shafir, Simonson and Tversky (1993) conclude, also on the grounds of the cited Payne et al. (1992),
"in contrast to classical theory that assumes stable values and preferences, it appears that people often do not have well-established values, and that preferences are actually constructed - not merely revealed - during their elicitation ..." (Shafir et al. (1993), p. 34$){ }^{3}$

Finally, the literature on cognitive dissonance reveals another, symmetric, source of endogeneity of preferences, namely the post-decisional adjustment of goals in order to rationalize counterintentional behaviours and outcomes (Fastinger (1956), Wicklund and Brehm (1976), and for an economic application Akerlof and Dickens (1982)).

All this lato sensu "cognitive" evidence suggest that, yes, we should primarily call in psychologists rather than decision-theorists in order to explain goal-formation, deliberation and choice.

Second, other pieces of evidence hint that we should call in social psychologists and sociologists, too. More precisely, one find widespread occurrences of social endogeneity of preferences, including social imitation, formation of relatively homogeneous "lifestyles" within specific social groups, "snob effects", authority-induced changes in values and choices, and many others. (A thorough discussion of a few of these issues with respect to consumption patterns is in Earl (1986)). Relatedly, within an enormous literature, see also, e.g. Milgram (1974), Maital and Maital (1993), Hirshman (1965), Kuran (1987), all the way to the suggestive conjectures on the historical dynamics of social adaptation and rebellion in Moore (1978)).

In these domains, T. Veblen is one of the outstanding early contributors of plenty of conjectures and 'appreciative theories' (for too long unjustly neglected, notwithstanding

\footnotetext{
${ }^{1}$ A rather balanced assessment of the merits and limitations of standard utility theory from an economist point of view is in Shoemaker (1982).

${ }^{2}$ One discusses some of them with an eye on their implications for evolutionary theories of learning in economics in Dosi, Marengo and Fagiolo (1996).

${ }^{3}$ See also Tversky and Simonson (1994).
} 
their, sometimes irritating, analytical fuzziness) ${ }^{4}$ cf. Veblen (1899) and (1919) (And, later, along somewhat similar lines, Duesenberry (1949),. Leibenstein (1950) and (1976); see also Katona (1975) and (1980)).

As already mentioned, it is worth recalling the caveat that under certain conditions the endogeneity of preferences as such does not pose any overwhelming challenge to standard decision theory. That includes those circumstances whereby, (a) the time-scale of preference evolution is of orders of magnitude greater than the time-scale of decisions themselves (so that, for example, the 'disutility of eating pork' might have evolved over millenia, but for all practical purposes that can be taken as a given and stable preference trait of any practising Jew or Muslim while selecting meat ... ); (b) preferences are not context-dependent, so that, in James March's language, they fulfil the conventional "logic of consequences" rather than a "logic of appropriateness" (... 'what is appropriate to do for anyone with my identity and my social role in those circumstances? ...') (cf. March (1994)); (c) future changes in preferences are fully anticipated by forward-looking intertemporally utility maximizers (cf. Becker (1976)) ${ }^{5}$ and (d) the collective distributions of preferences, at each time, are not among the arguments of individual decision algorithms (i.e. ... "like to do what my neighbours do" ... etc.). Here and throughout, we refer to 'social endogeneity' to mean those circumstances - in our view, quite frequent indeed - whereby those conditions are violated.

The two sets of evidence related, broadly speaking, first, to the cognitive and behavioural processes of choice, and, second, to their social embeddedness - strongly militate in favour of inductively disciplined theories of microeconomic behaviours, in general, and - as far as this work is concerned - final consumption, in particular, grounded into the relevant 'phenomenological' generalizations drawn from e.g. cognitive and social psychology, sociology, etc. It is a view certainly shared by those breeds of economists who might label themselves "behaviorist", "institutionalist" and "evolutionary" (for quite germane developments of this argument, Nelson and Winter (1982), Coriat and Dosi (1995), Hodgson (1988), and Earl (1986)). ${ }^{6}$

However, even granted all that (a point by no means uncontroversial among economists), why should we not let this domain of micro investigation to psychologists, sociologists (and psychiatrists), and limit our attention as economists to much more general, and, so to speak, "minimal" statistical restrictions on the characteristics of the populations of e.g. consumers which are sufficient for aggregate propositions on demand patterns to hold? ${ }^{7}$ If

${ }^{4}$ Consider for example the following citation from Veblen (1919):

An adequate theory of economic conduct, even for statical purposes must be drawn in terms of the individual simply - as in the case of the marginal-utility economics - ... since the response that goes to make up human conduct takes place under institutional norms and only under stimuli that have an institutional bearing ... The phenomena of human life occurs only as phenomena of the life of a group or community ... Not only is the individual conduct hedged about and directed by his abstract relations to his fellow in his group, but these relations, being of no institutional character, vary as the institutional xxx basics" (Veblen (1919), p. 242).

${ }^{5}$ cf. Sid Winter (1996) who tries to derive "endogenous" preferences from a sort of invariant "metautility functions".

${ }^{6}$ We must admit that we came across the latter quite late through the work leading to this paper - finding many overlapping points of view, and benefiting enormously from his thorough discussion of consumption theory and evidence. Significant parts of the argument which follows has been improved and refined drawing on that source.

${ }^{7}$ Of course, matter would look in any case quite different in fields like marketing or applied industrial economics, but for the time being we shall confine our discussion to those more general properties of 
we understand correctly, this is the perspective underlying the pioneering works of Trockel (1984) and especially Hildebrand (1994), whereby one attempts to establish the requirements for e.g. aggregate shapes of demand curves as functions of prices, entirely disposing of dubious psychological constructs based on "utilities", etc. and explicitly overcoming the aggregation problems undermining the extrapolation of the purported behaviour of single consumers to pseudo behavioural entities like "the representative agent". 8

In this approach, one is entirely agnostic on the ways preferences are formed (and whether they obey the consistency requirements of standard decision theories): rather, distributional invariances, together with budget constraints account for the aggregate patterns one is meant to explain. ${ }^{9}$ We do indeed believe that this is a highly promising route which one is just beginning to investigate. However, we also believe that the 'agnosticism' on behavioural microfoundations can go only part of the way in explaining observed "stylized facts" on demand. First, the question why distributions of revealed preferences are what they are seem to us an interesting one in its own right. Second, one might wonder how and when those distributions change - under the influence of e.g. introduction of new products, social interactions, etc. - and what implications all this bear in terms of aggregate demand properties. Note that both points are likely to be particularly relevant when one increases the number of empirical phenomena one tries to account for, e.g. in addition to the question of why demand schedule tend to be downward sloping, one investigates, together, the determinants of diffusion patterns of new commodities, the conditions of occurence of Engel-type demand profiles over time, or - even more complicated - the emergence of particular "norms of consumptions" within population of consumers or subgroup of them.

It is in these domains where we see a profound complementarity between behaviourally parsimonious statistical approaches - á la Hildebrand -, on the one hand, and constructive micro theories in a "Simonesque" and "Veblenesque" spirit, which indeed build upon what cognitive scientists, sociologists and tell us on choices and behaviours, on the other. In order to build that bridge, of course, a quite difficult task is to construct microfounded models which respect the spirit of the behavioural findings and, at the same time, are "abstract" enough as to generate stylized statistical properties of the ensuing aggregate demand profiles. This is indeed what we shall begin to do in the following.

Some disclaimers are in order. We are fully aware that the model we shall present is likely to be considered by empirically minded practitioners too much of a rape of the intricacies of consumers' behaviour, and, conversely, fare too complicated by theory-inclined readers: consider it just as a preliminary attempt within a largely unexplored field. The basic rationale of the exercise is to show how social processes of "preference learning" and innovation, in presence of stochastically growing incomes, can generate patterns of demand, and also patterns diffusion of new goods, statistically similar to those empirically observed. We are far from claiming that, by that token, this is "explaining" the evidence. More modestly, take it as an "exercise in plausibility", whereby, nothwithstanding heroic modeling assumptions, a few observed statistical properties of consumption can be constructively generated on foundations building on heterogeneous agents who are much

\footnotetext{
demand which one typically finds in any intermediate economics textbook.

${ }^{8}$ The fundamental inconsistencies of such a notion have been thoroughly discussed by Kirman (1989) and (1991). One of the points, among others, is that, even admitting individual maximizers, with well behaved utility functions, etc. aggregation does not carry over any restriction on the shape of the aggregate demand functions (i.e. the demand functions attributed to the "representative agent") without further ad hoc assumptions on the nature of preferences themselves. Complementarily, on the lack of ismorphism between micro-behavioural rules and aggregate dynamics of the corresponding time-series, cf. Lippi (1988).

${ }^{9} \mathrm{An}$ early modeling attempt to derive the sign of demand adjustments to price changes solely from budget constraints is in Sanderson (1974).
} 
less "rational" and much more social than in standard theories, and, who discover collectively "along the way" what they like and what they demand within a growing universe of available commodities.

In section (ii) we shall outline what, we suggest, are major building blocks of an evidence-disciplined theory of consumption behaviours. In many respects, they constitute ideal requirements for models still well down the road. Yet, they might be useful yardsticks for all those who do not buy into M. Friedman-type cavalier epistomology (... anything goes in terms of assumptions, provided that they turn out to somehow work in terms of predictions ...). Section (iii) introduces some modeling tools, including a modified version of Genetic Algorithms (drawing from John Holland (1975)), through which we try to capture in a highly simplified form the structures of preferences and their evolution over time. On these bases, we develop our model of consumption dynamics. Next, we study some statistical properties of demand generated through computer simulation (section iv). In the conclusions (section (v)), we also briefly hint at possible further developments toward "institutionalists" foundations of demand theory.

\section{Toward a Descriptive Theory of Consumption: Some Build- ing Blocks}

It is obviously impossible to provide here any fair account of the diverse pieces of evidence on the processes leading to consumption choices: a whole book would not be enough to adequately cover the findings, from marketing to cognitive sciences ... (See anyhow Earl (1986) for an ambitious overview and interpretation, and Robertson and Kassarjian (1991)). ${ }^{10}$ Here, we shall just try to abstract some properties which appear sufficiently general to be candidate as building blocks also for modeling efforts.

1. Consumption acts (as well as other economic behaviours) are nested into cognitive categories and 'mental models' of the actors.

As argued at some greater length in Dosi, Marengo and Fagiolo (1996), any theory of choice, behaviour and learning in complex and changing environments is most likely bound at some point to take explicitly on board the cognitive structures by which people frame the interpretations of their experience and their expectations. And consumption activities are no exception. Painstakingly, works from cognitive and social psychology and artificial sciences including Holland et al. (1986), Tversky and Kahneman (1986), Lakoff (1987), Johnson-Laird (1983) and (1993), Goffman (1974) are making timid inroads into economics; and, with reference to consumption theory, Earl (1986) makes extensive use of Kelly's Personal Construct Psychology (Kelly (1955)) and Steinbrunner's "cybernetic" approach (Steinbrunner (1974)). Notwithstanding the enormous diversity across these cited approaches, it seems to us, what they have in common for our rudimentary purposes is the general acknowledgement of the importance of diverse and possibly evolving mental models, cognitive categories and 'frames' shaping perception and deliberation.

2. The relationships between 'mental models', preferences and consumption behaviours are to some extent implicit and, possibly, also partly inconsistent with each other.

The fact that 'models' provide a structure through which people "make sense" of what they do (and, together, what they want) is likely to entail the emergence and reproduction of recognizable lifestyles (cf. Earl (1986)). However, these structures tend to be fuzzy and ridden with inconsistencies in terms of both actual choices and mapping between the latter and perceived goals (cognitive dissonance relates precisely to this phenomenon).

\footnotetext{
${ }^{10}$ This section which follows has benefitted a lot also for the insightful survey (unfortunately only available in Italian) on the evidence from the marketing and consumer behaviour literature by Devetag (1995).
} 
Conflicting preference structures and criteria for choice might precariously (and sometimes painfully) coexist within the same agent.

'Models' offer satisficing inferential machineries for choice (Legrenzi et al. (1993), Johnson-Laird (1993)). However, given their 'satisficing' nature, and their blurred links with (possibly conflicting) goals, a) they leave open "reason-based" decision-procedures:

"decisions ... ar often reached by focusing on the reasons that justify the selection of one option over another. Different frames, contexts and elicitation procedures highlight different aspects of the options and bring forth different reasons and considerations that influence decisions". (Shafir, Simonson and Tversky (1993), p. 34);

and, b) the choice process is often guided by heuristic criteria which might not bear any rigorous mapping into any underlying coherent structure of preferences. Note that point a) implies a sort of inseparability between preference-formation and preference-revelation (through the choices act): in a sense, preferences are constructed through the very process of deliberation. An implication, in this perspective, is that one cannot innocently separate some unequivocal objective (e.g. $\max \cup(., ., \cdot)$ ) from the algorithms for its implementation. Rather, mental and behavioural models are (rough) templates for the elicitation of both the choice procedures and what is to be preferred. Point (b) finds ample support from what in various models of consumer's behaviour are called non-compensatory criteria of choice (e.g. heuristics often based on hierarchical filtering procedures, 'focusing' upon salient aspects of the choice context, exercises of comparison with prototypical expectations, etc.): cf. Earl (1986) and Davetag (1995), and the references therein. ${ }^{11}$

3. Habits, routines and explicit deliberative processes coexist to varying degrees, as determinants of most consumption acts.

As Olshavsky and Granbois (1979) put it (also cited in Earl (1986)),

"For many purchases a decision process never occurs, not even on the first purchase ... Purchases can occur out of necessity; they can be derived from culturally mandated lifestyles or from interlocked purchases; they can reflect preferences acquired in early childhood; they can result from simple conformity to group norms or from imitation of others; purchases can be made exclusively on recommendations from personal or non-personal sources; they can be made on the basis of surrogates of various types; or they can even occur on a random or superficial basis ... Even when purchase behaviour is preceded by a choice process, [the latter] is likely to be very limited. It typically involves the evaluation of few alternatives, little external search, few evaluative criteria, and simple evaluation models". (Olshavsky and Granbois (1979), pp. 98-99.)

Clearly, the evidence on routinization of behavioural patterns is quite in tune with that taken on board and theorized upon, in other domains of economic activity, by various evolutionary approaches: cf. in particular Nelson and Winter (1982) and Cohen et al. (1996). And, of course, it fits well the ample sociological evidence on adaptation to specific social roles. ${ }^{12}$

\footnotetext{
${ }^{11}$ Interestingly this literature mainly from marketing or from experimental studies has drawn relatively little attention from the scholars more directly inspired by standard economic theory: cf., for example, the otherwise thorough and balanced discussions of models and statistical evidence of Brown and Deaton (1972) and Deaton and Muellbauer (1980). Note that, conversely, the 'compensatory' archetype of choice is a necessary condition for maximization over convex combinations of attributes (or goods) and prices. Attempts to hold together standard decision-theoretic assumptions and the acknowledgement of some nonconvexities in the purported utility sets have been made through so-called 'multi-attribute utility theory' (cf. Dyer et al. (1992); see also Fishburn (1974)).

${ }^{12}$ Incidentally, note that in the early works of G. Becker, one finds the possibility of explanations of economic behaviours based on habits rather utility maximization: cf. Becker (1962).
} 
More generally:

4. Consumption habit and routines, and, dynamically, their formation and acquisition, are embedded in the processes of socialization and identity-building.

The 'social embeddedness' notion of economic behaviours is obviously near the spirit of a lot of sociological thinking and evidence (for appraisals relevant for the current discussion cf., among others Granovetter (1985), Baron and Hannan (1994), Hodgson (1988); see also Dosi (1995) and Coriat and Dosi (1995) on the background of some of the ideas put forward here). Taken seriously, that view implies also that one should be wary of assuming any individual preference structures (or, for that matter, individual behavioural patterns) as sole 'primitives' of microfounded theories of economic behaviours. Rather, one from the start ought to account for explicit dynamics of collective adaptation. Multiple factors support this view. Some of them underlie the possibility of social bandwagon effects (Lebeinstein (1976)). Freely citing from Granovetter and Soong (1986, pp. 845), they include interpersonal correlations of preferences nested in (a) status seeking; (b) consumption externalities of whatever kind; and (c) the revealed outcome of other people's experiences as surrogate for one's own search. ${ }^{13}$ Even more profoundly, social adaptation also in consumption patterns is likely to be part of fundamental processes of identity-building, involving (imperfect) adaptation to the habits and norms of specific social groups. In this respect, many works of Bourdieu are suggestive illustrations of how the social context contributors to structure social behaviours and revealed preferences (cf. Bourdieu (1976) and (1979); see also Berger and Luckmann (1967)). ${ }^{14}$

However, at least in contemporary capitalist economies, adaptation to social roles is rather imperfect, ridden of conflicts and of multiple (possibly contradictory) archetypical identities, with these archetypes themselves changing rather quickly over time. ${ }^{15}$

As a consequence,

5. Habits and routines-formation hold varying and precarious balances with search and innovation.

Pushing it to some extreme, the idea is that a good part of the complement to one of routinized relatively automatic and repetitive, consumption patterns is not any canonically "rational" deliberative choice, but rather some wilder process of search/experimentation, whereby also some "utility" (whatever that means) is drawn from the very exploratory process. Whether or not one subscribed to the general anthropologic conjecture by Scilovsky (1992) on the intrinsic stimuli and pleasure brought about by novelty ${ }^{16}$, there is certainly strong empirical ground to the idea that, at least in a few circumstances, consumers 'experiment', 'explore', 'discover', develop novel 'consumption technologies' and lifestyles, etc. (cf. Earl (1986) and Bianchi (1997)). As with routines, we find here some loose analogy with the exploratory patterns of producers, much more investigated in the literature on the economics of technological innovation (cf. Freeman (1982), Rosenberg (1982), Dosi

\footnotetext{
${ }^{13}$ Conversely, differentiation effects may emerge as well, such as 'snob' inclinations to distinguish oneself from the revealed majority (and also more complex - "cognitively dissonant" - attitudes such as those summarized by Marx (Graucho), unwilling to "join any club which would accept him as a member ...")

${ }^{14}$ Straightforwardly, this point links with the previous ones on 'mental models' and 'lifestyles': in this perspective, the evolution of the latter is dynamically coupled with a social context framing the meanings and also the reinforcements (the "pleasures and pains") of individual experiences.

${ }^{15}$ For insightful discussions on potentially "multiple selves" pertinent to different domains of experience, cf. Elster (1986). A subtle issue, which cannot be pursued here is the relative "rational" coherence of each of the purported "selves": however, as it should be clear from the foregoing argument, we are inclined to depict a "self" (i.e. an identity) with a good deal of internal inconsistencies in both goals and procedures in order to achieve them.

${ }^{16}$ With a robust body of evidence from experimental psychology supporting it, notwithstanding equally robust examples of reinforcements to social adaptation.
} 
(1988), Nelson and Winter (1982)).

6. (Imperfect) social adaptation, learning - on both preferences and consumption 'technologies' - and search, all entail path-dependencies (at the very least at individual level).

By now, it is, at last, generally acknowledged that both collective externalities and dynamic increasing returns generally involve dependence of dynamic paths upon initial conditions (or, in richer stochastic formulations, the dependence of limit states upon early fluctuations). However, in a strange paradox, the relevance of this widespread phenomenon has been much more emphasized on the supply side of production and technological innovation (cf. among others, David (1985), Arthur (1988), Dosi (1997)), rather than on the final demand side. It is some paradox because on the supply side, microeconomic pathdependencies (for example, regarding the learning patterns of individual firms) might not exert long-term collective influences insofar as selection environments (e.g. markets) remain testbeds for different innovative trial-and-errors on the grounds of unchanged selection criteria (i.e. insofar as the "selection landscape" remains unchanged). Conversely, on the final demand side, agent-specific and collective path-dependencies are even more likely to arise, since there is no "selection environment" to speak of (after all everyone agrees that, except for ethical considerations, "de gustibus non est disputandum" ...). In its essence, the point had been already made by Duersenberry when taking issue against the assumptions that, first, "every individual's consumption behaviour is independent of that of every other individual, and [second], the consumption relations are reversible in time" (Duersenberry (1949), p. 1). ${ }^{17}$ Since then a lot of corroborating evidence on consumer behaviours has indeed supported both of Duersenberry's counterassumptions (cf. Earl (1986)), without, however, any appropriate acknowledgement in terms of demand theory.

7. From 'stylized facts' to theoretical first approximations: $\alpha$ ) complementarities within lifestyle-shaped consumption-systems; and, $\beta$ ) lexicographic patterns of consumer's selection over hedonic attributes and goods.

At least as a first cut, let us assume that (socially shaped) 'mental models' link together multiple - and, possibly, partly contradictory - goals, heuristics perceived to be appropriate to their achievement, and particular types of goods. After all, if different "lifestyles" exist, they ought to involve discretely different maps across these sets of variables. In turn, collectively shared models and behavioural patterns are likely to involve proximate complementarities in preference structures over both hedonic attributes of goods and goods themselves. (In an illustrative caricature, one is not very likely to find Ferrari drivers wearing chainstore shoes; or Mozart-fanatics content to listen to music on a walkman ...). Complementarities are, of course, enormously reinforced by 'harder' social interdependencies - like those linking patterns of spatial mobility, uses of leisure time, ownership of cars, service stations, presence of infrastructures like highways - etc. And, relatedly, mental models and social lifestyles add up to more mundane 'physical' hierarchies of needs in determining rough lexicographic orders of consumption priorities. Hence, on the top of rather predictable hierarchies from basic necessities (such as food) to more discretional expenditures, socially acquired norms and visions tend to drive proximate rankings over commodities, or classes of them well above the sheer physiological constraints. This does not mean of course that discretionality, 'choice', price-dependent substitution, etc. are

\footnotetext{
${ }^{17}$ Again path dependency at both individual and collective levels was among Veblen's intuitions, e.g. when emphasizing that "... institutions of today ... the present accepted scheme of life ... do not entirely fit the situation of today. At the same time, men's present habit of thought tend to persist indefinitely, except as circumstances enforce a change these institutions which have been handed down, these habits of thought ... mental attitudes ... are therefore themselves a conservative factor. This is the factor of social inertia, psychological inertia, conservatism" (Veblen (1899), p. 141).
} 
ruled out. On the contrary, cognitive and behavioural structures can be seen as a sort of basin of attraction allowing for a good deal of stochastic fluctuations where both explicit deliberations and path-dependent influences play major roles. However, we still maintain the hypothesis that while 'compensatory choices' might hold locally for butter vs. vegetable oil, etc., broader changes in consumption patterns are largely nested into deeper, discrete, changes in cognition and socialization models (and in ways possibly independent from any change in relative prices).

To sum up: a descriptive theory of consumption should in principle encompass relatively ordered "models" and "lifestyles" which path-dependently evolve through both (imperfect) social imitation and innovation. Can one capture at least some elements of this view in a formal model? This is what we shall address in the next section.

\section{The Model}

Since the representation of our agents is based on a modified version of Genetic Algorithms (GA), it is worth to start from a concise presentation of the latter (much more in Holland (1975) and Goldberg (1989)).

In essence a GA is based on the reproduction and modification of information coded on strings of finite length. In an analogy with DNA coding, think of a sequentially ordered set of elements (genes in the biological interpretations, demanded goods in the application which follows). Each element can take two or more alternative forms (or "alleles"): below straightforwardly it can have two states, 1 or 0 , that is the good is either demanded or not by any one consumer. ${ }^{18}$ Hence, for example, the string $\{01010\}$ encodes the fact that the consumer is going to demand only - reading from left to right - the second and the fourth good. GA's evolve through two operators, namely crossover and mutation.

Crossover entails a recombination over two "parent" GA's. For example, give two GA's, say,

$$
01010
$$

and

10011,

a random draw of an integer $K$ (in the case, $1 \leq K \leq 5$ ) determine, so to speak, the "cutting point" (say, 3). In this case the recombined strings will consist of the first three alleles of the first one and the last two of the second one,

01011

and, vice-versa, for the second "child":

10010

i.e. the first three of the second "parent" and the last two of the first one.

Mutation involves the change of state of any one random element on the sequence (from 0 to 1 or vice-versa).

In the standard formulation, strings are in turn selected over time according to their relative "fitness" as revealed by the environmental payoffs that they obtain. This will not be so in the model which follows. As already mentioned, there is no reason to think that some consumption pattern may be intrinsically "better" than another one, and, in

\footnotetext{
${ }^{18}$ For our purpose here we can neglect the element $(*)$ of the GA alphabet, meaning "wild cards" whose specification does not affect the overall performance of the string itself.
} 
any case, there is no collective mechanism (thank God!!) to check it. Therefore, more technically, our GA's evolve over a flat selection landscape, solely driven by crossover and mutation. The death process (of strings) in our model is only determined by the (timelagged) effects of budget constraints ( "... once upon a time, I desired to have a villa at Cap Ferrat, five servants and caviar every day ... however, I have now forgotten all that, and I am quite content with my little apartment and meat twice a week ..."). In the model that follows each element of the string encodes, as mentioned, one particular commodity (which might or might not be supplied at any particular time $t$ ). ${ }^{19}$

For our purposes here, GA's provide a simple (albeit inevitably rough) account of an evolving lexicographic order over the desired commodities, whose structure is indeed a proxy for the 'lifestyle' of the consumer ${ }^{20}$ Needless to say, the model of consumer behaviour that we propose is highly stylized and 'abstract' - possibly as 'abstract' as the standard utility based model. However, the assumptions that it incorporates are radically different from the latter in that it tries to capture (a) the social nature of preference formation; (b) the role of individual and collective history; (c) the formation (and change) of consumption habits; and (d) the permanent possibility of innovation. Contrary to the canonic decision model, we assume agents with extremely limited computational capabilities, but with the possibility of "learning their preferences" through the very process by which they select their consumption patterns. ${ }^{21}$

\section{Representation of Consumers}

At any time $t$ each consumer $j$ is characterized by:

- $y_{j}(t)$, its income level (in monetary terms);

- $r_{j}(t)$, the income class to which it belong (these classes endogenously change as income grow: see also below);

- $L_{j}^{\tau}(t)$, a binary string of length $l$ (with $l=$ number of actual and eventually possible goods), where each $i$ - element $(1, \cdots i \cdots l)$ takes the value of 1 or 0 depending to whether the corresponding good appears or not in the consumption pattern of consumer $j$. (In the simulations of the model which follows we set $l=223$.) Note also that goods are further distinguished according to their product group $g$ (below $g=1, \cdots, 5)$

- $S_{j}(t)$, a string of length $l$ coding the actual expenditures (in monetary terms) on each good $i$ (clearly, taking value zero for all goods which have a zero on the $L_{j}^{\tau}(t)$ string);

- $L_{j}^{f}(t)$, a binary string of length $l$, which we call "frustrated memory" where element $i(=1, \cdots l)$ takes value 1 if that good has been selected to be part of one's own consumption pattern but no purchase has yet been made due to the budget constraint. Note that whenever a purchase occur on any $i$ in $L_{j}^{f}(t)$, that $i$ will start to appear as " 1 " on the string of actual consumption patterns $L_{j}^{\tau}(t)$, and correspondingly disappear from the "frustrated memory" (a "1" will turn into a "0"). We shall see below how the frustrated memory emerges, as indirect outcome of innovation and

\footnotetext{
${ }^{19}$ In the latter case, of course, the corresponding value of that element will be zero for all consumers.

${ }^{20}$ Here and throughout, there is a major, and admittedly unresolved, ambiguity between preferences over 'attributes' vs. preferences over commodities. While we share with Earl (1986), and, before, Lancaster (1971), the idea that some underlying (hedonic) attributes and not commodities themselves are the object of consumption acts, our very simple model avoids any explicit account of the "cognitive" mappings between the former and the latter, and their evolution in the minds of consumers.

${ }^{21}$ More detail on a slightly different version of the model is in Aversi (1990).
} 
social imitation; moreover, it stochastically decays as exponential function of time (so that, "1"'s turn "radioactively" into "0"'s as time goes by);

- $S_{j}^{f}(t)$, a string of length $l$, listing the desired expenditures (in monetary terms) corresponding to the items which appear on the "frustrated memory".

This description of the consumers, together with the string $P(t)$, which is the systemlevel vector of unit prices $p_{i}(t)$ is sufficient to determine the actual quantities purchased by each $j .{ }^{22}$

Income dynamics

(Monetary) incomes of individual consumers are random walks with a drift so that

$$
y_{J}(t+1)=y_{j}(t)\left(1+\epsilon_{j}(t)\right)
$$

where $\epsilon_{i}(t)$ is an i.i.d. random variable drawn from a truncated normal $N\left(\mu, \sigma^{2}\right)$. Truncation is such to prevent for simplicity negative income changes (throughout the simulations presented here we assume $\mu=.03$ and $\mu=\sigma^{2}$ ).

Consumers do not save (except possibly for some residual involuntary saving, see below): hence in general income is equal to total expenditure (correspondingly, all commodities ought to be rigorously considered as "non-durables").

Income classes

We define $r$ income classes $(r=20$, initially set so that the higher value of the class exceed the lower one by $\mu \%$ (obviously, near the very beginning of the simulation most of the classes are going to be empty: see below on "initial conditions"). As incomes growth, the 20 classes are endogenously redefined so that they will continue to partition the whole population in 20 groups of log-identical sizes.

Old and new products

At the beginning of "history" (i.e. at $t=0$ ), available commodities are very few, and mainly concentrated in product group one (the metaphorical equivalent of "basic necessities"). Hence also most elements in the strings $L_{(\cdot)}^{r}(\cdot)$ and $P(\cdot)$ have value zero. However, at each time new commodities stochastically arrive, whose number is drawn from a Poisson distribution. Given that number, each virtual $i$ (that is each commodity which takes at $t-1$ a value zero on the price vector) has a uniform probability to come to existence. Consider all that as a simplified version of some unspecified dynamics of innovation on the supply side. Note that whenever a new commodity is born, it appears with a positive price in the $P(\cdot)$ vector. That, however, does not automatically imply that it is bought by any one consumer (see below on "innovation"). A commodity unsold for more that $\tau$ periods (in our simulations $\tau=3$ ) becomes "dead".

Commodity unit prices

When a commodity is introduced it is associated with a random price $p_{i}^{(0)}$, drawn from a uniform distribution defined on a finite support (in our simulations, $1 \leq p_{i}^{(0)} \leq 100$ ). We experimented with two versions of price dynamics. In version 1 ,

$$
p_{i}(t+1)=p_{i}^{(0)}\left(1+\epsilon_{i}(t)\right)
$$

\footnotetext{
${ }^{22}$ In the model we assume indivisibility of the first unit purchased, but divisibility over any amount above 1 (one might want to consider that as a very rough proxy of quality-related differentiation, albeit totally unspecified on the supply side, so that, for example "one and a half" unit of a commodity might be metaphorically understood as one unit plus added gadgets and optionals ...). We further add the convention that any commodity $i$ which is not actually produced at $t$ has price zero and obviously cannot be bought by any consumers.
} 
where $\epsilon_{i}(t)$ is an i.i.d. random variable drawn from a truncated normal distribution with zero mean, defined over $-1<-a \leq \epsilon \leq+a$.

In version 2 ,

$$
p_{i}(t+1)=p_{i}^{(0)}\left(\sum_{t} q_{i}(t)\right)^{\alpha_{i}}
$$

where $\alpha_{i} \leq 0$ and $q_{i}(t)$ stand for total quantities of the commodity sold at each $t$. In a nutshell, in version 1, prices are subject to uncorrelated random shocks, while in version 2 , they fall as a function of cumulated sales, in a fashion similar to what is often suggested in the literature on "learning curves" and dynamic increasing returns.

Dynamics of individual consumption

At each "period" after individual incomes have been updated, each consumer faces four stochastic alternatives, namely,

1. Leave unchanged the consumption basket, with probability $\theta^{u}$. In the following we have assumed $\theta_{i}^{u}$ identical for all $i$ 's and experimented with different parametrizations, ranging from .2 to .8). Under this option, all budget items are identically increased in proportion to income growth. ${ }^{23}$

2. Access the 'frustrated memory' with probability $\theta_{i}^{f}$. In this case, all income increase is in principle devoted to the purchase of one or more items which, as mentioned, had been acquired as part of the chosen "lifestyle" but could not be bought due to the budget constraint. (Note that despite income growth, the addition of new items to the actual consumption basked is not necessarily guaranteed: see below on "adjustment algorithms").

3. Change (part) of the consumption patterns via innovation or imitation with probability $\left(1-\theta_{i}^{m}-\theta_{i}^{f}\right)$. In our model, quite in tune with the evidence on innovation diffusion $^{24}$, we have assumed that, once the consumer has stochastically "decided" to change, the innovative option (i.e. adopt a new product) is a function of its income class, $r_{i}{ }^{25}$. The complement to one is the effort to imitate, which, we assume, is restricted to one's own income class and higher ones (if any). Imitation has clearly to do also with phenomena of social integration, formation of (partially) homogeneous lifestyles within similar social groups or, conversely, efforts to sanction upward social mobility. A rough way to capture all that is by assuming that the consumer to be imitated is drawn from a Poisson-type distribution with mean 1 (for the purposes of this draw we reclassify income classes, so that we indicate with zero the class to which the consumer belongs, with 1 that immediately higher, etc.). ${ }^{26}$

\footnotetext{
${ }^{23}$ That hypothesis amount to assuming, under this option, a homothetic demand function with unitary price elasticities of demand. It is an extreme assumption, running counter a lot of evidence on different price- and income-elasticities of different goods. We made in just in order not to inbuild any possible emergent properties of the model into the assumptions. Hence, for example, if Engel-type patterns in budget coefficients were to emerge, they ought to be solely due to the dynamics of preference evolution and not to some pre-imposed preference structure differently weighting different goods as incomes grow. Of course a fortiori, the conclusions would hold in a more realistic model that would allow for both preference evolution and "intrinsic" propensities e.g. to trade off "inferior" and "superior" goods.

${ }^{24}$ See for example Rogers (1983). Discussions of evidence and models of innovation diffusion from different angles are in Mahajar, Muller and Bass (1989), Dosi (1992) and Stoneman (1995).

${ }^{25} \mathrm{We}$ assume that the probability of innovating is distributed as an exponential function of the income classes.

${ }^{26}$ Since the distribution will have a truncation corresponding to the highest income class, probabilities are proportionally reassigned to the relevant income classes.
} 


\section{3a. Innovation}

If the consumer has opted, so to speak, for the "exploration" route, it randomly draws (within a uniform probability distribution) one of the "new" products which have become available (see above) but are not included in its desired consumption patterns of that particular consumer.

\section{3b. Imitation}

Conversely, under the imitation made, after having selected the income class to be imitated, through the above procedure, a consumer is randomly selected in that class, and, together, a random product group from $g$. Next, the crossover operator from GA's is applied to the substring corresponding to that product aggregate and that consumer. ${ }^{27}$ In that way, the imitator "borrows" so to speak, part of the preference structure of the imitated agent, and in a first approximation, also its budget allocation to the corresponding items (that is the relevant parts of the strings $L_{k}^{\tau}(t-1)$ and $S_{k}(t-1)$, with $k$ being the imitated agent). ${ }^{28}$

\section{Adjustment algorithms}

Given the indivisibility of the first unit of any item of consumption (cf. footnote 18) changes in the consumption patterns - no matter whether due to access to the "frustrated memory", innovation or imitation - do not necessarily fulfill the budget constraint. If they do, the new consumption profile will be implemented (with any possible income residual being subject again to the same stochastic allocation process described so far (i.e. between "no change", memory-activation, imitation, innovation). If the new consumption profile, on the contrary, violates the budget constraint, an iterated procedure of adjustment is implemented checking whether relatively "local" adjustments can accomodate for the new desired expenditures. The steps are the following:

a) check if reductions of expenditures over up to 5 goods within the same product group are sufficient to make up to the novel desired expenditure (under the requirement of a minimal unitary expenditure on the former);

b) same as sub a) plus the reduction of desired quantities of new items to one unit each;

c) same as b), but with the added possibility of giving up entirely up to 2 "old" goods;

d) same procedure as a) and b), but with the expenditure reduction applicable to the whole consumption string (up to a maximum of 10 items);

e) same procedure as c), again applied to the whole string.

We assume that the corresponding changes in consumption patterns always occur when either steps a) or b) generate budget-consistent schedules, while they happen only in probability in cases c) to e) (with the probability falling from the former to the latter). ${ }^{29}$

This algorithm, as simple as it is, is meant to capture the relative inertia and pathdependency of "models of consumption" and related "lifestyles". Moreover, note that when only part of the new desired expenditures can be fulfilled, in the spirit of our earlier considerations on lexicographic hierarchies in consumption, the order of priorities goes

\footnotetext{
${ }^{27}$ Out of the two substrings so obtained, the imitator is assumed to retain that which has on the righthand the preferences of the imitated consumer. (Recall that the whole string can be read from left to right as going from "old" to "new" products, and in terms of product aggregates, from necessities to more discretional items of expenditure ...)

${ }^{28}$ In fact, we allow also with small probability a sort of 'involuntary innovation' to occur through the imitation process, in so far as the relevant part of the $L_{k}^{\tau}(\cdot)$ sting is imperfectly copied (with a "0" instead of " 1 " or vice-versa).

${ }^{29}$ In order to prevent nearly infinite recursions, we stipulate that whenever the income to be allocated is less than $5 \%$ of the total disposable income, that will be added to next period income as a sort of "involuntary savings".
} 
"from left to right" on the string, in terms of product groups. Whenever, after the mentioned adjustment iterations, some (or all) desired new expenditures remail unfulfilled, they transit upon the "frustrated memory".

\section{Initial Conditions}

At time zero, we assume consumers (1000 in the following) with an identical (and low) income and identical preferences over a small number of initially available commodities (below, 5 goods of which 3 within group 1, i.e. "necessities").

One of the purposes of the model is precisely to see whether, notwithstanding these initial conditions and the quite simple dynamics described above, the model can generate as sorts of emergent properties ${ }^{30}$ some of the regularities that one generally detect in the empirically observed consumption patterns.

\section{A Preliminary Look At Some Statistical Properties}

Let us begin by noticing that the model endogenously generates differentiation in individual consumption patterns, and, at the same time, entails processes of social imitation which prevents such diversity from exploding. Despite totally uniform initial conditions, as incomes stochastically grow, both patterns of consumptions and "preferences" evolve in ways that are path-dependent and socially embedded. Path-dependency appears at two levels: first, the individual consumption patterns at any time depend also on the sequence of past "preferences" and consumption acts, second, indirectly, they depend on the whole collective history of the latter. Relatedly, the social embeddedness of the dynamics is straightforward, in that preferences and revealed purchasing patterns emerge from collective mechanisms of social imitation, which represent also ordering mechanisms, possibly accounting for the relative predictability of aggregate patterns over time. ${ }^{31}$ Finally, the model allows the persistent exploration of new items of consumption - and through that, an everlasting evolution of "lifestyles". (In the present model, almost entirely focused on the demand side, this implies that implicit dynamics on the supply side provide co-evolving opportunities of innovation). ${ }^{32}$ Given all that, an important "exercise in plausibility" (although not a rigorous validation of the model itself) is, as mentioned in the introduction to this work the analysis of the patterns of consumption generated by the model. ${ }^{33}$

\section{Diffusion Patterns}

Figures 1 and 2 depict two quite typical diffusion profiles that the model generates, displaying the usual S-shape generally found in the empirical diffusion patterns (cf. among others, Rogers (1983), Mahajan et al. (1989), Grübler and Nakicenovic (1992)). With regards to empirical data, one often finds in the literature estimates of the rate equations

\footnotetext{
${ }^{30}$ For a detailed discussion of this notion, cf. Lane (1993).

${ }^{31}$ Incidentally, note that our model does not appear to display, under the parameterizations which we explored, those phenomena of sudden "regime transitions" and possibly chaotic behaviour predicted by the model of social imitation of Granovetter and Soong (1986). Our intuition is that this does not happen here, first, because of the higher path-dependency, and thus "inertia" inbuild in our model. Second, here consumer tend to imitate consumption bundles and not individual items, implying also a slower and more imperfect drive to social uniformity (since the imitated bundles are generally different from each other). However, it does not seem unlikely that Granovetter and Soong's properties could emerge in modified versions of this model allowing for e.g. "fashion" goods, faster rates of imitation on them and sampling mechanisms for the imitation with respect to the imitated population.

${ }^{32}$ Note, incidentally, that empirically testing restrictions on a purported (and unobservable) "utility function" does not have a much different epistemological status.

${ }^{33}$ The simulations discussed in the following are based on 500-period runs with 1000 agents. Unless otherwise specified the results which we present hold for the whole range of parametrizations on the "inertia" consumption patterns (i.e. the probability of sticking to the past basket composition) which we varied from .2 to .8. Similarly, they hold under both versions of price dynamics (see above).
} 
of the diffusion process as a (non-linear) function of the number of potential adopters and of the total number of consumers who have already adopted the commodity in their consumptin basket. A typical model is some discretization of a rate equation such as

$$
\frac{d N(t)}{d t}=a \bar{N}+(b-a) N(t)-\frac{b}{\bar{N}}(N(t))^{2}
$$

when $N$ stands for the total number of adopters at $t, \bar{N}$ is the number of potential adopters, the parameter $a$ is meant to capture the "autonomous" (i.e., in our language, "innovation-related") adoption choices and $b$ is the "imitation-related" choices - nonlinearly dependent on $N$ - (cf. Mahajan et al. (1989)). (Note also that in our model as well as in reality, "older" commodities may be driven out of the consumption baskets by the arrival of new ones.) For sake of illustration, we report in Appendix 1 one of the estimates of the discrete reformulation of (4)

$$
s(t)=\alpha+\beta(N(t-1))+\delta(N(t-1))^{2}
$$

where $s(t)$ is the net arrival of new adopters at $t$. Notwithstanding their widespread use, however, estimates of models like (5) are ridden with serious econometric problems (see Appendix 2). Hence, we do not want to make much out of it. Let us simply state primarily as a conjecture apparently not contradicted by the data that "autonomous" innovation in consumption, and, together, social imitation do not only appear in the "microscopic" description of how agents evolve their consumption patterns, but they seem to carry over to the "macroscopic" description of system dynamics.

Engel-type Dynamics of Consumption Patterns and Structural Instability

As mentioned earlier, in order not to bias by construction our results, we have made the extreme (and unrealistic) hypothesis that, when consumers opt for the reproduction over time of their past consumption patterns they do so in a way that amounts to assuming a homothetic demand with unitary price elasticity. It is interesting to check whether despite this assumption, long-term changes in budget coefficients emerge, driven by social innovation and imitation, jointly with stochastically growing incomes. Remarkably, they do, displaying Engel-type patterns of evolution in the share of different product groups. This type of dynamics appears must evidently in the case of group 1 (a metaphorical proxy for "necessities") and group 5 (which, being on the right-hand part of the consumption string is, in probability, "filled up" after more basic necessities have been satisfied): see Figures 3 and 4. More rigorously, Tables 1 and 2 (Appendix 2) report estimates (over subperiods) of a model of the form

$$
b_{g}(t)=\alpha+\beta t+g_{1} \log y_{t}+\delta_{2} \log y_{t-1} \cdots+\lambda_{1} p_{1}+\lambda_{2} p_{2} \cdots \lambda_{5} p_{5}+\epsilon_{t}
$$

where $b_{g}(t)$ are the shares in aggregate consumption of product groups $g(g=1$, Table 1 and $g=5$, Table 2), $t$ is a time trend; $y_{t} \cdots y_{t-\tau}$ are the simultaneous and lagged per capita real incomes and $p_{1} \cdots p_{5}$ are the values of the price index of each product group (the simulations have been carried out under the stationary/stochastic price version: see above and Appendix 2).

Price-coefficients although with the negative sign are not generally significant (neither in the estimates shown here nor in most other tests that we have carried out) - which is not too surprising given our extreme assumptions. What is much more interesting is the significant effect of both a trend component and lagged incomes, yielding Engeltype patterns which are purely an aggregate emergent property, driven by the collective exploration of new consumption opportunities, together with the progressive relaxation of budget constraints. 
Tests on other simulation results, not shown here, conducted on "version 2" of price dynamics (i.e. prices falling along with "learning curves") suggest a model specification where all variable are I (1). (Hence the analyses have been carried out on the differences of the logs of the variables.) While in general Engel-type patterns continue to emerge, also prices (both the price index of the group in question and of the others) appear often to exert a significant influence of the dynamics of budget shares (up to the fifth lag, and mostly but not always with the expected sign). However, note that, again, this should be considered an emergent property which does not bear any isomorphism with microscopic behaviour: in fact, by construction, individual agents either have unit price elasticities when acting "business-as-usual" or do not look at all at prices when imitating or innovating - except in sofar as prices affect budget constraints. Indeed, what appears in the aggregate as the dynamic influence of prices upon shares rests in fact on the process by which the fall in the former help relaxing budget constraints (a sort of a dynamic version of an income effect) and that in turn makes easier innovation, imitation and fulfillment of "frustrated" options.

Moreover, in empirical time prices, one often detects evidence of important and generalized structural breaks in the patterns of consumption within and across product groups (on the former, cf. Combris (1992); more generally on changes in consumption patterns, cf. Houthakker ((1957) and (1965)), Kuznets (1962), Gardes and Louvet (1986), Deaton and Muellbauer (1980)). Remarkably, notwithstanding our rather rudimentary behavioural assumptions, structural instability - most often emerges when testing so-called "quasi-ideal" models of longitudinal expenditure patterns (cf. Deaton and Muellbauer (1980), Blundell, Pashardes and Weber (1993)) - with respect to both commodity groups and within groups shares of individual commodities. When applying the usual tests for structural stability (Chow, CUSUM, and CUSUMSQ), one generally finds (especially with regards to aggregates 1 and 5) significant structural change, intertwined by rather long periods of structural stability. At the risk of some overinterpretation, these patterns might suggest the easy emergence of puntuated discontinuities in historically shaped, collectively shared, "models of consumptions", which however display a "metastable" character (in the sense that they persist on time scales of orders of magnitude greater that those of the processes which generated them, but nonetheless tend to vanish with probability one as time goes on). ${ }^{34}$

'Demand Laws' With Innovative Exploration and Social Adaptation

As emphasized in the introduction to this work, a crucial question concerns the robustness of aggregate economic propositions, such as "demand laws", well beyond those circumstances whereby aggregate dynamics is presumed to exactly map into corresponding behavioural patterns of some purported 'representative' (most often, utility-maximizing) agent. A major advantage of a model such as that presented here is that one is bound to specify the microscopic decision algorithms, which, in our case, are clearly at odds with any assumption of both a) statistical invariance in some 'revealed preferences', and, at least equally important, b) algorithmic coherence in the choice process. Do well-established pieces of conventional economic wisdom - such as downward sloping demand schedules for individual commodities - hold in these cases too?

As mentioned in the introduction, this is precisely the question addressed by Hildebrand (1994), in a perspective which is on purpose much more agnostic about microeconomic decision rules. Here, having constructed the data generating process we may also try to establish the nature of the underlying micro conditions under which "demand law"

\footnotetext{
${ }^{34} \mathrm{~A}$ stimulating discussion of metastability notions in the domain of evolutionary models in economics is in Lane (1993). Conversely, on the recurrence and economic importance of specific social "norms of consumption", cf. the broad historical interpretations in Aglietta (1979) and Boyer (1986).
} 
type propositions apply. As a premise, note that we have already touched the issue, from a dynamic point of view, hinting that, for commodity aggregates, seemingly "well-behaved" demand schedules might (often but not always) emerge out of the interactions between price changes, dynamic income effects, social imitation, relaxation of budget constraints ...

However, "laws of demand" as commonly depicted starting from undergraduate courses in economics, imply a major static (with respect to time) thought-experiment. That is, despite the fact that at any given time one obviously observes only one price/quantity combination, what would happen if the price of the commodity at hand were higher/lower holding constant all other system parameters and micro decision rules? Hildebrand (1994) proves indeed some sufficient conditions for standard demand-law propositions (and weaker versions thereof) to hold, which carry observationally testable implications concerning the distribution of demand patterns, at any $t$, conditional on different income classes (cf. Appendix 3).

One of the basic ideas is that if the distribution of preferences - irrespective of how they formed (or, for that matter, of how coherent they are) - is sufficiently homogeneous across income cohorts, one can establish sufficient conditions to guarantee non-upward-sloping notional demand curves (at each $t$ ), whose fulfilment can be detected from the statistical properties of actual demand conditional on different income classes.

In brief, a "law of demand" (LD) is verified (i.e. the demand function $F_{t}(p)$ is strictly monotonically decreasing) if for any pair of price vectors $p$ and $p^{\prime}$ (with $p$ different from $\left.p^{\prime}\right)$

$$
\left(p-p^{\prime}\right)\left(F_{t}(p)-F_{t}\left(p^{\prime}\right)\right)<0
$$

A weaker version is represented by the so-called Wald axiom (WA), that is

$$
\left(p-p^{\prime}\right) F_{t}\left(p^{\prime}\right) \leq 0 \quad \text { implies } \quad\left(p-p^{\prime}\right) F(p) \leq 0
$$

or in the strict formulation, where

$$
\left(p-p^{\prime}\right) F_{t}\left(p^{\prime}\right) \leq 0 \quad \text { implies } \quad\left(p-p^{\prime}\right) F(p)<0
$$

The "law of demand" satisfies Wald Axiom but the converse is not true. The bottom line is how to establish the conditions under which the LD and the WA are verified without imposing corresponding restrictions on (unobservable) individual demand schedules. These conditions turn out to be related to various measures of dispersion of demand patterns across income cohorts: cf. Appendix 3.

In that appendix we show that, indeed, under some parametrizations of our model the conditions for the WA (and also for the LD) are satisfied. Note, again, that this is another emergent property of the model which does not necessarily find any direct isomorphism into micro behavioural rules. It is also interesting to observe under which specifications of the model these properties hold. The results presented in Appendix 3 apply under the stationary-price version, with relatively high inertia in individual consumption patterns. ${ }^{35}$ However, as an admittedly preliminary exploration of different parameter values show that the LD and WA properties tend to be lost as one increases the probability of innovating (and this is so, above some threshold, also if one correspondingly increases the probability of imitating, too).

Our conjecture is that in fact the fulfilment of the conditions for the LD and WA to hold are ultimately determined by (imperfect) social imitation, so that the distribution of

\footnotetext{
${ }^{35}$ In the simulations analyzed there the probability of sticking to the past is .8 ).
} 
notional "preferences" - or "desired lifestyles" - are not too different across income classes, together with the different impact that budget constraints exert on actual expenditures of consumers (so that, loosely speaking, with higher incomes, the "cloud" of commodity combinations corresponding to each consumer tend to be more dispersed). ${ }^{36}$

However, if innovative behaviours acquire a major role in the evolution of individual consumption patterns the relative homogeneity of the distribution of "preferences" across income classes (i.e. what Hildebrand (1994) calls "metonymy" of demand schedules) tends to be lost, and with that also the aggregate statistical properties sufficient for the validation of the "law of demand" and of the Wald Axiom. Let us state this conjecture in a more extreme and provocative way: a) whenever one abandons the assumptions of well-behaved micro preference functions together with rather demanding and quite ad hoc restrictions on their distributions, aggregate LD and/or WA properties might continue to hold as statistical collective properties (these are Hildebrand's results); however, b) what basically determines these aggregate properties are ultimately phenomena of social imitations, together with budget constraints; and, relatedly, c) sufficiently fast processes of "autonomous" consumer innovation might also imply the breakdown of conventional assumptions on (static) inverse relations between prices and demanded quantities.

\section{Conclusions}

In this work, building on what we consider to be some general empirical properties of consumption decisions and their evolution, we have developed a simple model which tries to capture - albeit in a very rudimentary form - phenomena like the existence of recognizably different "lifestyles", lexicographic orders on consumption acts, (limited) path-dependency of individual and collective consumption patterns, innovation and social imitation. It turns out that, despite its simplicity, the model generate emerging aggregate patterns of consumption with statistical properties quite in tune with empirically observed regularities, such as S-shaped diffusion of new commodities, Engel-type dynamics of budget shares, and under quite a few micro parametrizations, distributions of consumption coefficients yielding in the aggregate notional downward sloping demand curves. Of course, one can think of several improvements upon both the model and the exploration of the statistical properties of the data it generates.

Concerning the model, one can easily imagine two complementary directions. On the one hand, one might gain many insight from models which, paraphrasing Malerba et al. (1996), are more "evidence-friendly", in that they take on board much more detailed phenomenological specifications on e.g. cognitive processes of formation of 'lifestyles', decision rules, different characteristics of commodities, "consumption technologies", etc. (For example, it is obvious that the distribution between durables vs. non-durables, necessities vs. discretionary items, etc. are likely to map also into different decision rules ...). In the same vein, sooner or later, one will have to tackle the challenge of providing more rigorous accounts of coevolutionary processes among consumption acts, preferences and cognitive representations (as pleaded, with reference to other economic domains, in Marengo and Tordjman (1996) and Dosi, Marengo and Fagiolo (1996)). In the other direction, one might want to explore the properties of even more reduced form models with some hope

\footnotetext{
${ }^{36}$ Note that the two propositions are not in conflict with each other- the first one claims that "desired lifestyles" are relatively similar across income groups (of course one assumes on that several such "lifestyles" coexist at any $t$ ). The second proposition holds that as one goes from one income cohort to a higher one, the dispersion of actual consumption baskets will increase because under a relaxed budget constraint more of those desired (and cross-sectionally diverse) 'lifestyles' will be satisfied.
} 
of studying analytically some generic invariances in the ensuing statistical properties. ${ }^{37}$

With respect to statistical follow-ups, what we have tried here are just a few and rather naive attempts to check the coherence between the properties of the data generated by the model and those observed in actual history. Ahead, there are obviously more rigorous exploration of the robustness of the results (including Montecarlo-type exercises holding parametrizations constant, and systematic comparisons across sample paths generated under different parametrizations and behavioural assumptions). Moreover, one may envisage - as mentioned earlier - promising interactions between analyses establishing parsimonious sufficient statistical conditions for aggregate economic propositions to hold (such as those, discussed above, proved by Hildebrand (1994) on notional "demand laws") and explicitly microfounded models that might illuminate the classes of data-generating processes yielding certain aggregate statistical outcomes.

As Veblen one century ago, an increasing number of scholars still feel today the importance of nesting the interpretation of economic phenomena upon microfoundations different from coherent self-seeking monads with well-behaved "utility functions" and extraordinary calculating capabilities. In this perspective, the foregoing work is hopefully moving some modest steps forward in the direction of an evolutionary (and socially grounded) theory of demand, still to come.

\section{References}

Aglietta, N. (1979). A Theory of Capitalist Regulation, London, New Left Books.

Akerlof, G.A. and W.T. Dickens (1982). "The Economic Consequences of Cognitive Dissonance", American Economic Review, 72, pp. 307-19.

Aversi, R. (1990). Razionalita, Istituzioni, Innovazione: una Applicazione degli Algorithmi Genetic alle Decisioni di Consumo, "Laurea" Dissertation, Rome, Faculty of Statistics, University of Rome "La Sapienza".

Arthur, B.W. (1988). "Competing Technologies: An Overview", in: Dosi G. et al. pp. 590-607.

Baron J. and M. Hannan (1994). "The Impact of Economics on Contemporary Sociology", Journal of Economic Literature, 32, pp. 1111-1146.

Baxter, J.L. (1993). Behavioural Foundations of Economics, London, Macmillan.

Baxter, J.L. and I.A. Moosa (1996). "The Consumption Function: A Basic Needs Hypothesis", Journal of Economic Behaviour and Organization, 31, pp. 85-100.

Becker, G.S. (1962). "Irrational Behavior and Economic Theory", Journal of Political Economy, 70, pp. 1-13.

Becker, G.S. (1976). The Economic Approach to Human Behavior, Chicago, University of Chicago Press.

Becker, G.S. (1996). Accounting for Targets, Cambridge, MA, Harvard University Press.

Berger, P.L. and T. Luckman (1967). The Social Construction of Reality, Harmondsworth, Penguin.

Bianchi, M. (ed.) (1997). The Active Consumer, London, Routledge (forthcoming).

\footnotetext{
${ }^{37}$ In this mode, one can intuitively see fruitful overlapping with much simpler (and more elegant and analytically tractable) models of socially evolving preferences, such as Brock and Durlauf (1995). Relatedly, note that, in principle, our consumption model might be possibly be reformulated as some Markov process in some high dimensional (or infinitely dimensional) state space.
} 
Blundell, R. (1988). Consumer Behaviour: Theory and Empirical Evidence. A Survey", Economic Journal, 98, pp. 16-65.

Blundell, R., P. Pashardes and G. Weber (1993). "What Do We Learn About Consumer Demand Patterns from Micro Data?", American Economic Review, 83, pp. 570-97.

Bourdieu (1976). "Goutes des classes et styles de vie", Actes de la Researche en Sciences Sociales.

Bourdieu (1979). La Distinction, Paris, Eol. Minuit.

Boyer, R. (1986). La Theorie de la Regulation, Paris, La Decouverte.

Brock, W.A. and S. Durlauf (1995). Discrete Choice With Social Interaction. Part I: Theory, Madison, University of Wisconsin, Working Paper.

Brown, A. and A. Deaton (1972). "Surveys in Applied Economics: Models of Consumer Behaviour", Economic Journal, 82, pp. 1145-236.

Cohen, M., N. Burkhart, G. Dosi, M. Egidi, L. Marengo, M. Warglien and S. Winter (1996). "Routines and Other Recurring Action Patterns of Organisations: Contemporary Research Issues", Industrial and Corporate Change, Vol. 5, 3, pp. 653-698.

Combris, P. (1992). "Changements structurels: le cas des consommations alimentaires en France de 1949 á 1988", Economie et Prevision, 4.102-103, pp. 221-45.

Coriat, B. and G. Dosi (1995). The Institutional Embeddedness of Economic Change. An Appraisal of the 'Evolutionary' and 'Regulationist' Research Programmes, Laxenburg, IIASA, Working Paper, WP-95-117.

David, P.A. and R.W. Reder (eds.), Nations and Households in Economic Growth. Essays in Honor of Moses Abramovitz, New York, Academic Press.

David, P.A. (1985). "Clio and the Economics of QWERTY", Amercian Economic Review, Papers and Proceedings,

Deaton, A. and J. Muellbauer (1980). Economics and Consumer Behaviour, Cambridge, Cambridge University Press.

Deaton, A. (1992). Understanding Consumption, Oxford, Oxford University Press.

Devetag, G. (1995). Bias, euristiche e rappresentazioni nella teoria del consumatore: un inventario ragionato, Venice, University of Venice, Business School, mimeo.

Dosi, G. (1988). "Sources, Procedures and Microeconomic Effects of Innovation", Journal of Economic Literature,

Dosi, G., C. Freeman, R. Nelson, G. Silverberg and L. Soete (eds.) (1988). Technical Change and Economic Theory, London, Francis Pinter and New York, Columbia University Press.

Dosi, G. (1992). "Reserch on Innovation Diffusion: An Assessment", in: A. Grübler and N. Nakicenovic (Eds.), Innovation Diffusion and Social Behaviours, Heidelberg/Berlin/New York, Springer-Verlag.

Dosi, G. (1995). "Hierarchies, Markets and Power: Some Foundational Issues on the Nature of Contemporary Economic Organisations", Industrial and Corporate Change, 4, pp. 1-19.

Dosi, G., L. Marengo and G. Fagiolo (1996). Learning in Evolutionary Environments, Working Paper, WP-96-124, November 1996, IIASA, Laxenburg, Austria.

Dosi, G. (1997). "Opportunities, Incentives and the Collective Patterns of Technological Change", Economic Journal, forthcoming. 
Duesenberry, J. (1949). Income, Savings and the Theory of Consumer Behavior, Cambridge, MA, Harvard University Press.

Dyer, J.S., P.C. Fishburn, R.E. Stuer, J. Wallius and S. Zionts (1992). "Multiple Criteria Decision-Making, Multiattribute Utility Theory: The Next Ten Years", Management Science, 38, pp. 645-55.

Elster, I. (1984). Ulysses and the Sirens, Cambridge, Cambridge University Press, 2nd ed.

Elster, I. (ed.) (1986). The Multiple Self, Cambridge, Cambridge University Press.

Earl, P. (1986). Lifestyle Economics. Consumer Behaviour in a Turbulent World, Brighton, Wheatsheaf/Harvester Press.

Fastinger, L. (1956). A Theory of Cognitive Dissonance, New York, Harper and Row.

Fishburn, P.C. (1974). "Lexicographic Orders, Utilities and Decision Rules: A Survey", Management Science, 20, pp. 1442-71.

Freeman, C. (1982). The Economics of Industrial Innovation, London, Francis Pinter, 2nd edition.

Gardes, F. and Ph. Louvet (1986). La Convergence internationale des structures de consommation, Paris, CREDOC.

Goffman, E. (1974). Frame Analysis. An Essay on the Organisation of Experience, Harmondsworth, Penguin.

Goldberg, D.E. (1989). Genetic Algorithms in Search, Optimization and Machine Learning, New York, Addison-Wesley.

Granovetter, M. (1985). "Economic Action and Social Structure: The Problem of Embeddedness", American Journal of Sociology, 51, pp. 481-510.

Granovetter, M. and R. Soong (1986). "Threshold Models of Interpersonal Effects in Consumer Demand", Journal of Economic Behaviour and Organisation, 7, pp. 8399.

Hildebrand, W. (1994). Market Demand, Princeton, Princeton University Press.

Hirschman, A. (1965). "Obstacles to Development: A Classification and a Quasi-Vanishing Act", Economic Development and Cultural Change, 13, pp. 385-93.

Hodgson, G. (1988). Economics and Institutions, Cambridge/Oxford, Polity Press/Basil.

Hodgson, G.N. (ed.) (1993). The Economics of Institutions, Aldershot, Edward Elgar.

Hogart, R.M. and N.W. Reder (eds.) (1986). Rational Choice, Chicago, University of Chicago Press.

Holland, T.H. (1975). Adaptation in Natural and Artificial Systems, Ann Arbor, MI, University of Michigan Press.

Holland, T.H., K.J. Holyoak, R.E. Nisbett and P.R. Thagard (1986). Induction. Processes of Inference, Learning and Discovery, Cambridge, MA, MIT Press.

Houthakker, M.S. (1957). "An International Comparison of Household Expenditure Patterns, commemorating the centenary of Engel's Law", Econometrica, 25, pp. 532-51.

Houthakker, M.S. (1965). "New Evidence on Demand Elasticities", Econometrica, 33, pp. $277-288$.

Iannacone, L.R. (1989). "Bandwagons and the Threat of Chaos. Interpersonal Effects Revisited", Journal of Economic Behaviour and Organisation, 11, pp. 431-42. 
Johnson-Laird, P.N. (1983). Mental Models, Cambridge, MA, Harvard University Press.

Johnson-Laird, P.N. (1993). The Computer and the Mind, London, Fontana Press, 2nd ed.

Katona, G. (1975). Psychological Economics, Amsterdam, Elsevier.

Katona, G. (1980). Essays in Behavioral Economics, Ann Arbor, MI, University of Michigan, Institute for Social Research.

Kelly, G.A. (1955). The Psychology of Personal Constructs, New York, Norton.

Kirman, A. (1989). "The Intrinsic Limits of Modern Economic Theory: The Emperor Has No Clothes", Economic Journal, 99, 395, pp. 126-39.

Kirman, A. (1991). "Whom or What Does the Representative Individual Represent?", Journal of Economic Perspectives, 6, pp. 117-36.

Kuran, T. (1987). "Preference Falsification, Policy Continuity and Collective Conservation", Economic Journal, 97, pp. 642-55.

Kuznets, S. (1962). "Quantitative Aspects of the Growth of Nations. VII: The Share and Structure of Consumption", Economic Development and Cultural Change, 10, pp. $1-92$.

Lakoff, G. (1987). Women, Fire and Dangerous Things. What Categories Reveal About the Mind, Chicago, University of Chicago Press.

Lancaster, K.J. (1971). Consumer Demand. A New Approach, New York, Columbia University Press.

Lane, D. (1993). "Artificial Worlds and Economics", Parts I and II, Journal of Evolutionary Economics, 3:89-107 and 177-197.

Leibenstein, H. (1950). "Bandwagon, Snob and Veblen Effects in the Theory of Consumer Demand", Quarterly Journal of Economics, 64, pp. 183-207.

Leibenstein, H. (1976). Beyond Economic Man. A New Foundation For Microeconomics, Cambridge, MA, Harvard University Press.

Legrenzi, P., V. Girotto and P.N. Johnson-Laird (1993). "Focussing in Reasoning and Choice", Cognition, 49, pp. 37-66.

Levy-Garbona, L. (1986). "Innovation et diffusion des produits de consommation", Economie Appliquée, 39, pp. 521-82.

Lippi, M. (1988). "On the Dynamics of Aggregate Macroequations: From Simple Microbehaviours to Complex Macrorelationships", in: Dosi et al. Technical Change and Economic Theory.

Mahajan, V., E. Muller, and F.M. Bass (1989). Dynamics of Innovatin Diffusion: New Product Growth Models in Marketing, E.L. Cox School of Business, Southern Methodist University, Dallas, Texas, mimeo.

Maital, S. (1982). Minds, Markets and Money. Psychological Foundation of Economic Behavior, New York, Basic Books.

Maital, S. and S.L. Maital (eds.) (1993). Economics and Psychology, Aldershot, Edward Elgar.

Malerba, F., R. Nelson, L. Orsenigo, and S. Winter (1996). A Model of the Computer Industry, Milan, Bocconi University, Milan.

March, J.G. (1994). A Primer on Decision-Making, New York, Free Press. 
Marengo, L. and H. Tordjman (1996). "Speculation, Heterogeneity and Learning: A Model of Exchange Rate Dynamics", Kyklos, 47.

Milgram, S. (1974). Obedience to Authority. An Experimental View, London Tavistock Institute.

Moore, B.M. (1978). Injustice. The Social Bases of Obedience and Revolt, New York, Pantheon Books.

Nelson, R.R. and S.G. Winter (1982). An Evolutionary Theory of Economic Change, Cambridge, RA, the Belknap Press of Harvard University Press.

Olshavsky, R.W. and D.H. Granbois (1979). "Consumer Decision-Making - Fact or Fiction?", Journal of Consumer Research, 6, pp. 93-100.

Osherson, D. and E. Smith (eds.) (1990). An Invitation to Cognitive Science, Cambridge, RA, MIT Press.

Payne, J.W., T.R. Bettman and E.J. Johnson (1992). "Behavioural Decision Research: A Constructive Process Perspective", Annual Review of Psychology, 43, pp. 87-131.

Robertson, T.S. and H.H. Kassarjian (eds.) (1991). Handbook of Economic Behaviour, Englewood Cliffs, Prentice-Hall.

Rogers, E.M. (1983). Diffusion of Innovation, New York, Free Press, 2nd ed.

Rosenberg, N. (1982). Inside the Blackbox, New York/Cambridge, Cambridge University Press.

Sanderson, W.C. (1974). "Does the Theory of Demand Need the Maximum Principle?" in: David and Reder (1974).

Schoemaker, P.J.H. (1982). "The Expected Utility Model: Its Variants, Purposes, Evidence and Limitations", Journal of Economic Literature, 20, pp. 529-63.

Scitovsky, T. (1992). The Joyless Economy. The Psychology of Human Satisfaction, New York/Oxford, Oxford University Press.

Sen, A. (1977). "Rational Fools: A Critique of the Behavioural Foundations of Economic Theory", Philosophy and Public Affairs, 6, pp. 317-344.

Shafir, E., I. Simonson and A. Tversky (1993). "Reason-Based Choice", Cognition, 49, pp. 11-36.

Simon, H.A. (1959). "Theories of Decision-Making in Economics and Behavioural Sciences", American Economic Review, 49, pp. 253-83.

Simon, H.A. (1986). "Rationality in Psychology and Economics", in: Hogart and Reder (1986).

Simon, H.A. (1988). Models of Thought. Vol. I, New Haven, Yale University Press, 2nd ed.

Slovic, P. (1990). "Choice", in Osherson and Smith (1990).

Steinbrunner, J.D. (1974). The Cybernetic Theory of Decision, Princeton, Princeton University Press.

Stoneman, P. (ed.) (1995). Handbook of the Economics of Innovation and Technological Change, Oxford, Basil Blackwell.

Stigler, G.T. and G.S. Becker (1977). "De gustibus non est disputandum", American Economic Review, 67, pp. 76-90. 
Thaler, R. (1980). "Toward a Positive Theory of Consumer Choice", Journal of Economic Behaviour and Organization, 1, pp. 39-60.

Thaler, R. (1992). The Winner's Curse. Paradoxes and Anomalies of Economic Life, New York, Free Press.

Trockel, W. (1984). Market Demand: An Analysis of Large Economies with Non-Convex Preferences, Berlin/Heidelberg/New York, Springer-Verlag.

Tversky, A. and D. Kahneman (1986). "Rational Choice and the Framing of Decisions", Journal of Business, 59, pp. 251-78.

Tversky, A. and I. Simonson (1993). "Context-Dependent Preferences", Management Science, Vol. 39, No. 10, pp. 1179-1189.

Veblen, T. (1899). The Theory of the Leisure Class, 1934 edition, New York, Random House.

Veblen, T. (1919). The Place of Science in Modern Civilization and Other Essays, 1990 edition, New Brunswick, Transaction Publishing.

Wicklund, R.A. and J.W. Brehm (1976). Perspectives On Cognitive Dissonance, Hillsdale, NJ, Erlbaum. 